\title{
The sex ratios of probands and of secondary cases in conditions of multifactorial inheritance where liability varies with sex
}

\author{
William H James
}

\begin{abstract}
Some pathological conditions affect one sex more often than the other. A curious feature of some of these conditions (dyslexia, congenital dislocation of the hip, pyloric stenosis, otosclerosis, lupus erythematosus, ankylosing spondylitis) is that the sex ratio (proportion of males) of randomly ascertained probands is more extreme than that of their affected relatives.

In all these conditions, multifactorial inheritance has been suspected. A simple model is offered here of multifactorial inheritance with liability varying by sex. Under the model, such a disparity between sex ratios would be expected.
\end{abstract}

Many pathological conditions are reported to affect one sex more frequently than the other. In some conditions (for example, dyslexia) difficulties in diagnosis or bias in ascertainment have been invoked in explanation. However, in others there can be no doubt that real differences exist, and such an interpretation is consistent with the remissions and relapses (for example, in rheumatoid arthritis and lupus erythematosus) experienced by women as they proceed through different phases of the menstrual and life cycles. $^{1}$

Table 1 gives estimates of the ratios of the sexes of randomly ascertained probands with various conditions. A curious feature of many of these conditions is that the sex ratio of probands is more extreme than that of secondary cases (that is, those ascertained by being related to a proband). The point has been commented on in regard to dyslexia, ${ }^{8}$ otosclerosis, ${ }^{9}$ and ankylosing spondylitis, ${ }^{10}$ and similar features can

MRC Mammalian Development Unit, University College London, Wolfson House, 4 Stephenson Way, London NW1 2HE.

W H James

Received for publication 25 May 1990

Accepted for publication 25 June 1990. be noted (from data in the cited references) in regard to lupus erythematosus, ${ }^{6}$ congenital dislocation of the hip, and pyloric stenosis. ${ }^{2}$ Table 1 gives data illustrating the point.

Commentators have responded variously to the point. Tallal $e t a l^{8}$ were frankly puzzled by it in regard to dyslexia. Morrison and Bundey ${ }^{11}$ noted that secondary cases are likely to be more closely scrutinised than probands, and they accordingly suggested that, in regard to otosclerosis, the more balanced sex ratio of secondary cases indicated bias in the ascertainment of primary cases, men being less likely to report deafness than women. Bodmer ${ }^{10}$ suggested that in ankylosing spondylitis the secondary cases may be less severe than the primary cases, and that this accounted for the disparity between their sex ratios.

Without directly impugning these explanations, I should like to describe a model which suggests a general explanation for conditions in which sex ratios of probands are more extreme than those of their affected relatives. In a condition in which males have a higher mean liability than females, and in which liability is to some extent inherited, one may represent the distributions of liabilities of males and females in the general population and in those who are relatives of probands as in the figure.

The sex ratio (proportion of males) of affected is the area under the male curve to the right of the threshold expressed as a proportion of the sum of the areas under the male and female curves to the right of the threshold. Let us assume that (1) the variances of male and female liability are equal, (2) the variances of liability in male and female sibs of probands take the same value, and (3) the difference between the mean liabilities of males and females in the general population is equal to the difference between the mean liabilities of male and female sibs of cases.

One may define the distribution of liability as normal. This does not make an unwarranted assumption about the real nature of the liability: it simply specifies that in order to express the degree of liability, we shall choose a scale of measurement which, if we could measure the liability, would yield a normal distribution. Then it may be confirmed that 
Table 1 Sex ratios of randomly ascertained probands and of their affected sibs: selected pathological conditions.

\begin{tabular}{|c|c|c|c|c|}
\hline Condition & Source & $\begin{array}{c}\text { SR of } \\
\text { probands }\end{array}$ & $\begin{array}{l}\text { SR of } \\
\text { affected sibs } \\
\text { of probands }\end{array}$ & Source \\
\hline $\begin{array}{l}\text { Congenital dislocation of the hip } \\
\text { Pyloric stenosis } \\
\text { Lupus erythematosus }\end{array}$ & $\begin{array}{l}\text { Carter }^{2} \\
\text { Carter }^{2} \\
\text { Wallace and } \\
\text { Dubois }\end{array}$ & $\begin{array}{l}0 \cdot 12 \\
0 \cdot 80 \\
0 \cdot 10\end{array}$ & $\begin{array}{l}0 \cdot 21 \\
0 \cdot 73 \\
0 \cdot 32\end{array}$ & $\begin{array}{l}\text { Carter }^{2} \\
\text { Carter }^{2} \\
\text { Arnett }^{6}\end{array}$ \\
\hline Otosclerosis & Larsson 4 & 0.33 & 0.5 (approx) & $\begin{array}{l}\text { Larsson }^{4} \\
\text { Morrison }^{7}\end{array}$ \\
\hline Ankylosing spondylitis & Masi $^{5}$ & 0.76 & 0.62 & Masi $^{5}$ \\
\hline
\end{tabular}

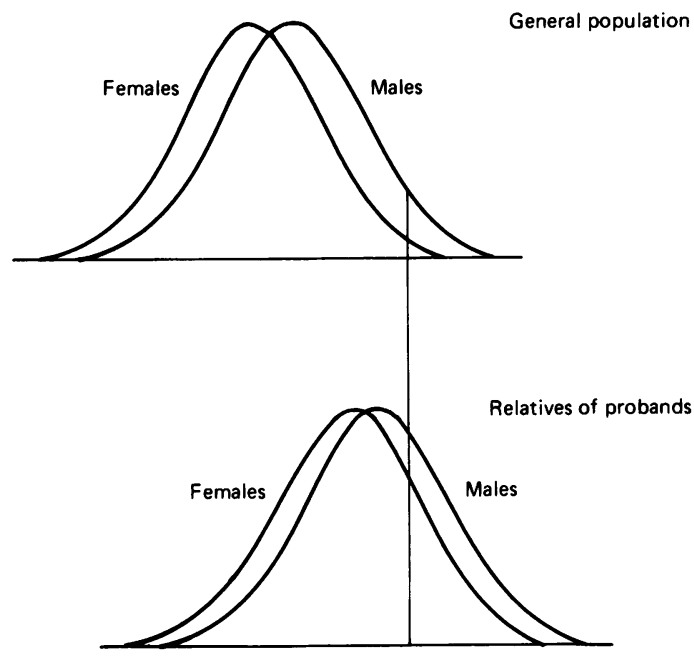

Hypothesised distributions of liability in a condition in which males have greater liability than females. It will be seen that the sex ratio of the affected

Area under the male curve to the right of the threshold

Area under the male curve to the right of the threshold + area under the female curve to the right of the threshold

is lower in the lower pair of distributions.

the sex ratio of affected relatives of probands is not as extreme as that of the probands themselves: the sex ratio of affected relatives lies between that of the probands and that of the total population. The point may be made clearer by taking illustrative values of mean liability measured in standard deviation values from the threshold (table 2).
It is worth noting that what is presented above is a model, not an infallible criterion. If the assumptions underlying the model are false, then explanations based on it may be false. All the conditions mentioned in table 1 have been suspected of being based on multifactorial inheritance. The grounds for such suspicion will not be summarised here. However, the fact that the present considerations add weight to those suspicions suggests, in general, that when sex ratios of probands are more extreme than those of their affected relatives, multifactorial inheritance should be suspected.

It is useful to assess whether the magnitude of effect expected on the model approximates to that found empirically. If the assumptions underlying the model are observed, then there is a relationship between the following four parameters: (a) sex ratio of randomly chosen probands, (b) sex ratio of affected sibs of probands, (c) overall population risk of the condition, and (d) risk to sibs of probands.

If we know the sex ratio of randomly ascertained probands and their incidence, we can estimate the difference (in standard deviation measure) between the mean liabilities of males and females. For instance, using the data of Carter $^{2}$ on congenital dislocation of the hip, one would estimate the male incidence at about 1 in $4000(=0.00025)$ and the female incidence at 7 in $4000(0.00175)$. The ordinates corresponding to these areas in the tail of a normal curve stand at 3.48 and $2.92 \mathrm{SD}$ from the mean, a difference of $0.56 \mathrm{SD}$.

The overall sib risk reported by Carter $^{2}$ was $66 / 1480=0 \cdot 0446$, and the ordinate corresponding to this area is $1.7 \mathrm{SD}$ from the mean. If the model were mirroring reality, the male and female thresholds would be roughly $0.28(=0.56 / 2) S D$ above and below

Table 2 Sex ratios of probands and of their sibs given illustrative values of distances from the threshold (in SD) of mean liabilities of males and females in the general population and those who are sibs of probands.

\begin{tabular}{lccc}
\hline & $\begin{array}{c}\text { Mean distance } \\
\text { from threshold }\end{array}$ & $\begin{array}{c}\text { Area under curve } \\
\text { beyond threshold }\end{array}$ & SR of affected \\
\hline General population, females & $2 \sigma$ & 0.023 & 0.74 \\
General population, males & $11 / 2 \sigma$ & 0.066 & 0.62 \\
Sisters of probands & 0 & 0.309 & 0.62 \\
Brothers of probands & 0 & 0.5 & \\
\hline
\end{tabular}


this value, that is, 1.98 and 1.42 for males and females respectively. The areas beyond these thresholds are 0.0239 and 0.0778 , and the sex ratio (proportion of males) of affected sibs predicted by the model is thus 0.235 as contrasted with the observed value of 0.212 . The difference is not significant and the fit is good. Applying similar methods to the data of Carter ${ }^{2}$ on pyloric stenosis, the sex ratio of sibs of cases predicted by the model is 0.71 and the observed value is 0.73 . Again, the fit is excellent.

It would be useful if similar demonstrations could be given in respect of the other conditions mentioned in table 1. However, (1) estimates of the sex ratio of patients with lupus are very variable. For instance Wallace and Dubois ${ }^{3}$ reviewed five large studies on cases in the USA: in these, the proportions of males varied from 0.04 to 0.22 . This being so, a convincing demonstration (that the model fits the data) would necessitate the use of estimates of the four parameters (a-d above) which all refer to the same population. I know of no such data. (2) I know of no precise numerical estimates of sib risk in otosclerosis. (3) $M^{2}{ }^{5}$ reviewed six population studies on ankylosing spondylitis. Here too, the sex ratios of affected were very variable, suggesting (as with lupus above) that one would need estimates of the four parameters (a-d) from the same population. Such data are not available to me.

However, these points are perhaps not important.
The essential thing is that a simple model is able to account for the very wide disparities between sex ratios (of probands and their affected relatives) observed in some conditions. It may prove applicable to other conditions too.

1 Carlsten H, Holmdahl R, Tarkowski A, Nillson LA. Oestradioland testosterone-mediated effects on the immune system in normal and autoimmune mice are genetically linked and inherited as dominant traits. Immunology 1989;68:209-14.

2 Carter $\mathrm{CO}$. Genetics of common single malformations. $\mathrm{Br}$ Med Bull 1976;32:21-6.

3 Wallace DI, Dubois EL. Definition, classification and epidemiology of systemic lupus erythematosus. In: Wallace DJ, Dubois EL, eds. Dubois' lupus erythematosus. 3rd ed. Philadelphia: Lea \& Febiger, 1987:15-32.

4 Larsson A. Otosclerosis: a genetic and clinical study. Acto Otolaryngolica (Suppl) 1960;154:1-86.

5 Masi AT. Epidemiology of B27-associated diseases. Ann Rheum Dis 1979;38 (suppl):131-4.

6 Arnett FC. Familial systemic lupus erythematosus, the HLA system and the genetics of lupus erythematosus. In: Wallace DJ, Dubois EL, eds. Dubois' lupus erythematosus. 3rd ed. Philadelphia: Lea \& Febiger, 1987:161-84.

7 Morrison AW. Genetic factors in otosclerosis. Ann R Coll Surg Engl 1967;41:202-37.

8 Tallal P, Ross R, Curtiss S. Unexpected sex ratios in families of language learning-impaired children. Neuropsychologia 1989;27: 987-98.

9 James WH. Sex ratios in otosclerotic families. $\mathcal{f}$ Laryngol Otol 1989;103:1036-9.

10 Bodmer WF. Discussion following Childs B, Finucci JM. In: Porter R, O'Connor M, eds. The genetics of learning disabilities. Human genetics: possibilities and realities. CIBA Foundation Symposium 66. Oxford: Excerpta Medica, 1979:376.

11 Morrison AW, Bundey SE. The inheritance of otosclerosis. f Laryngol Otol 1970;84:921-32. 